

\title{
Recommendations for ICT use in Alzheimer's Disease assessment: Monaco CTAD expert meeting
}

Philippe Robert, A. Koening, S. Andrieu, Francois Bremond, I. Chemin, Pau-Choo Chung, Jean-François Dartigues, B. Dubois, A. Feutren, R. Guillemaud, et al.

\section{To cite this version:}

Philippe Robert, A. Koening, S. Andrieu, Francois Bremond, I. Chemin, et al.. Recommendations for ICT use in Alzheimer's Disease assessment: Monaco CTAD expert meeting. Journal of Nutrition, Health \& Aging, 2013, 17 (8), 10.1007/s12603-013-0046-3 . hal-01059583

\section{HAL Id: hal-01059583 \\ https://hal.inria.fr/hal-01059583}

Submitted on 1 Sep 2014

HAL is a multi-disciplinary open access archive for the deposit and dissemination of scientific research documents, whether they are published or not. The documents may come from teaching and research institutions in France or abroad, or from public or private research centers.
L'archive ouverte pluridisciplinaire $\mathbf{H A L}$, est destinée au dépôt et à la diffusion de documents scientifiques de niveau recherche, publiés ou non, émanant des établissements d'enseignement et de recherche français ou étrangers, des laboratoires publics ou privés. 


\title{
Recommendations for ICT use in Alzheimer's Disease assessment:
}

\section{Monaco CTAD expert meeting}

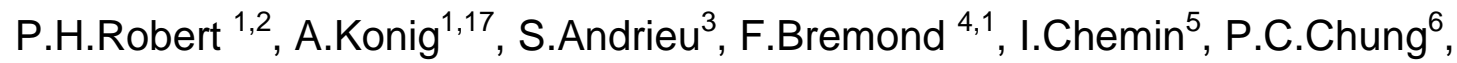 \\ J.F.Dartigues $^{7}$, B.Dubois ${ }^{8}$, G.Feutren ${ }^{9}$, R.Guillemaud ${ }^{10}$, P.A.Kenisberg ${ }^{11}$, S.Nave ${ }^{12}$, \\ B.Vellas ${ }^{13}$, F.Verhey $^{14}$, J.Yesavage ${ }^{15}$, P.Mallea ${ }^{1,16}$
}

Affiliations :

${ }^{1}$ EA CoBTeK, University of Nice Sophia Antipolis, France

${ }^{2}$ Centre Mémoire de Ressources et de Recherche, CHU de Nice, Nice, France.

${ }^{3}$ Inserm, UMR1027, F-31000 Toulouse, France ; Université de Toulouse III, UMR1027, F-31000

Toulouse, France ; CHU de Toulouse, Service d'épidémiologie et santé publique, F-31000 Toulouse, France

4 INRIA - STARS - Sophia Antipolis, France

${ }^{5}$ Association Chemin des sens

${ }^{6}$ National Cheng Kung University, Taiwan

${ }^{7}$ CMRR CHU de Bordeaux ,INSERM, ISPED, Centre INSERM U897-Epidemiologie-Biostatistique, Bordeaux, France

${ }^{8}$ CMRR CHU de Paris, IM2A, INSERM, UMR-S 975 (ICM), Hôpital La Salpêtrière, Université Pierre et Marie Curie-Paris 6

${ }^{9}$ Global Development, Novartis Pharma AG, Basle, Switzerland

${ }^{10}$ Electronique et Système pour la Santé DTBS -CEA, Grenoble, France

${ }^{11}$ Fondation Médéric Alzheimer

12 pRED, Neuroscience, Roche, Basle, Switzerland

13 INSERM UMR 1027 , Gerontopole, CHU Toulouse, Université de Toulouse

14 Alzheimer Centrum Limburg, School of Mental health and NeuroSciences, Maastricht University Medical Center, Maastricht, the Netherlands

${ }^{15}$ Palo Alto Veterans Affairs Health Care System, Palo Alto, CA and Department of Psychiatry and Behavioral Sciences, Stanford University School of Medicine, Stanford University, Stanford, CA

${ }^{16}$ Centre National de Référence Santé à domicile et autonomie (CNR Santé)

${ }^{17}$ University of Maastricht, Faculty of Psychology and Neuropsychology, Department of Psychiatry and Neuropsychology, Maastricht, The Netherlands

Corresponding author: Pr Philippe.H.ROBERT

EA CoBTek - Centre Mémoire de Ressources et de Recherche

Pavillon Mossa, Hôpital de Cimiez 4 av Victoria 06000 - Nice FRANCE

E mail: probert@unice.fr 


\section{Abstract :}

Alzheimer disease (AD) and other related dementia represent a major challenge for health care systems within the aging population. It is therefore important to develop better instruments for assessing disease severity and disease progression to optimize patient's care and support to care providers, and also provide better tools for clinical research.

In this area, Information and Communication Technologies (ICT) are of particular interest. Such techniques enable accurate and standardized assessments of patients' performance and actions in real time and real life situations.

The aim of this article is to provide basic recommendation concerning the development and the use of ICT for Alzheimer's disease and related disorders.

During he ICT and Mental Health workshop (CTAD meeting held in Monaco on the 30th October 2012) an expert panel was set up to prepare the first recommendations for the use of ICT in dementia research. The expert panel included geriatrician, epidemiologist, neurologist, psychiatrist, psychologist, ICT engineers, representatives from the industry and patient association.

The recommendations are divided into three sections corresponding to 1 / the clinical targets of interest for the use of ICT, 2/ the conditions, the type of sensors and the outputs (scores) that could be used and obtained, 3 / finally the last section concerns specifically the use of ICT within clinical trials. 
Alzheimer disease $(A D)$ and other related dementia represent a major challenge for health care systems within the aging population. Today clinician and researchers already used in clinical practice or in clinical trials several robust standardised tools such as the Mini Mental Score Examination (MMSE) for cognitive global assessment [1], the Alzheimer Disease Assessment Scale (ADAS) to measure the severity changes of the most important cognitive symptoms [2], the Neuropsychiatric Inventory (NPI) interview for Behavioral and psychological symptoms [3] and the Clinical Dementia Rating (CDR) to quantify the severity of symptoms of Dementia [4]. In $A D$, "dementia" is diagnosed when the disease has reached the stage where cognitive or behavioral (neuropsychiatric) symptoms interfere with social functioning or instrumental activities of daily living [5] (E). It is also recommended that the core clinical criteria, based on "functional impairment", should be used to diagnose all causes of dementia, including AD, in all clinical settings [6] (E).

Dementia is a diagnosis merely based on clinical judgement, for which appropriate assessment instruments are of vital importance. Finding a reliable method to assess functional impairment is of high interest since disease domains other than cognition are increasingly recognized as important outcome measures in clinical practice as well as in clinical trials for anti-dementia drugs. The choice of outcome measures in these trials is often constrained by tradition and availability. Therefore, cognitionbased psychometric measures are usually the preferred option. However, the clinical relevance and "meaningfulness » of such measures has been questioned as they may not adequately identify responders to therapy or address important aspects of outcome [7] (E). One of the main limitations remains that clinical assessments through questionnaires, scales or observations risk bias resulting from the assessor's 
subjectivity or the usually interviewed caregiver. Due to the time restraint, clinicians have often just limited access to diagnosis relevant information, particularly in cases of patients lacking awareness of their own condition. Neuropsychological tests are generally accused of being artificial and lacking ecological value. Furthermore, test results can show variability depending on many factors such as emotional state and may therefore not always fully reflect a patient's capacities and the complexity of the disease, which can lead to delayed diagnosis.

In this line, Information and communication technology (ICT) may be of great interest because they enable the patients' performances and actions to be captured and accurately evaluated in real time and real life situations.

Additionally, ICT is a means to cope with the increasing number of patients with chronic diseases in our aging society. As indicated by Eghdam \& al (2012) [8] for individuals with chronic illness affecting cognitive capacities either directly (eg, dementia) or indirectly (eg, diabetes), ICT has become a fundamental part in their daily lives by providing a wide range of useful services and tools to use at home, work, or anywhere else [9].

Over the last few years, research has focused on the development and use of various sensors to monitor activities of the elderly as well as of $A D$ patients. These include cameras and microphones for activity recognition [10] embedded sensors [11] or sensors placed on the body [12].

For instance, as part of the EXERCISE-ON study [13] whereas the impact of physical exercise on the progression of dementia symptoms was investigated, an actiwatch was used in order to monitor activity levels over a longer period of time objectively. 
Other studies propose the use of such device for the screening of sleep/wake disorders [14], agitation [15] or depression [16]. With the help of infra-red sensors for motion detection, Banerjee et al. [17] developed an automated surveillance system that identifies correctly $89 \%$ sequences of movement in comparison with manual analysis. Within a telecare project to help elderly people in France [18], a multisensor home monitoring system has been developed to observe mobility changes that may indicate abnormal events.

European Union also recognizes the confronting issues encountered by the aging populations and has initiated Framework Programme (FP 6 and FP7) to support the research into the development of process for healthy aging, biomedical advances, as well as prevention and disease management. For example, the successful FP6 COGKNOW project (http://www.cogknow.eu/) was strongly user-driven with 42 people with dementia and their informal careers involved throughout the project in specifying and testing functionalities in the four most important areas of unmet needs (memory support, daily activities, social contacts and feeling safe). In the FP7 project CONFIDENCE (http://www.confidence-eu.org/), monitoring of elderly takes place for unusual event detection and setting off the relevant alarms, but there is no direct focus on dementia, with life-logging and the appropriate feedback, such as cognitive exercises, not being offered to the people with dementia. The FP7 Hermes project (http://www.fp7-hermes.eu/) offers memory support for elderly with normal agingrelated cognitive decline. Similarly, the MemoryLane project (http://www.memorylane.nu/) aima at capturing pictures of the life of people with mild dementia.

However these ICT devices are mostly research prototypes which have not been completely validated. Data analysis methods are tested by using simulated 
physiological data. The detected activities are mostly only to measure simple motion patterns. Furthermore, these devices still need to be validated against clinically accepted standards in a clinical environment. Most of the works done on home sensing previously have been tested with a small number of users in experimental environment or at the researchers' homes and their affiliates. While there has been progress on the algorithms that monitor elderly people's homes and interpret the signals of the sensors, what is acquired is often very limited.

Nonetheless, clinical expertise and scientific literature review indicates that ICT are not able today to provide a direct diagnosis of Alzheimer's disease (AD) and related disorders. However, ICT provide information for the assessment of specific domains (behaviour, cognition, activity of daily living) and those indicators contribute with other clinical and biological data to the diagnosis of $A D$ and related disorders.

The aim of this article is to provide recommendation concerning the development and the use of ICT for Alzheimer's disease and related disorders.

\section{METHOD}

CoBTek (for Cognition - Behaviour - Technologies) is a Research Unit at SophiaAntipolis University (UNS) in Nice, France. CoBTek missions are, using Information and Communication Technologies, and most particularly imaging and video analytic techniques: 1/ To improve diagnostic and treatment of behavioural and cognitive symptoms in Alzheimer disease and related disorders 2/ To develop new strategies in order to prevent, help and assist elderly people 3/ To improve autonomy in the elderly.

The ICT and Mental Health workshop took place during the CTAD meeting in Monaco on the 30th October 2012. The workshop was organized by the CoBTeK 
team and the Centre National de Référence Santé à domicile et autonomie. An expert panel was set up to prepare the first recommendations for the use of ICT in dementia research. The expert panel included geriatricians, epidemiologists, neurologists, psychiatrists, psychologists, ICT engineers, and representatives from the industry and patient association. The starting presentation was held by the CoBTeK team as well as the discussion, which was audio recorded. The letter $(E)$ after an article reference number indicates if the reference is related to the expert presentation and discussion directly at the time of the meeting. Two drafts of the recommendations regarding the use of ICT in AD were circulated to experts in December 2012. It includes a literature review, which is summarized in Table 1. about different studies using ICT for monitoring and screening purposes in elderly subjects. For the review research articles and reviews dating from the year 1998 to 2012 were identified in PubMed using the following search terms : "dementia OR alzheimer OR mild cognitive impairment » AND «assessment OR evaluation OR sreening OR monitoring» AND « new methods OR new technologies OR ICT OR (Information and Communication Technologies) OR actigraphy OR infra-red sensors OR assistive technologies OR smart homes OR GPS ». Searches were limited to articles written in English. The experts were encouraged to revise their former comments provided during the meeting in ligh of the 2 drafts.

\section{RECOMMENDATIONS}

The recommendations are divided into three sections corresponding to $1 /$ the clinical targets of interest for the use of ICT, $2 /$ the conditions, the type of sensors and the outputs (scores) that could be used and obtained, 3 / finally the last section concerns specifically the use of ICT within clinical trials. 


\section{1/ What are the Clinical targets ?}

\section{COGNITION:}

Cognitive tests are assessments of human cognitive capacities. The administered tests include various forms. Throughout the 20th century, "paper and pencil" cognitive tests were commonly used to measure intelligence, assist with the diagnosis of brain disorders such as Alzheimer's disease, and measure recovery from brain disease or injury.

The first computerized cognitive tests were developed in the 1970s [19]. Computerized testing offers accurate recording of reaction times, electronic capture and processing of data (minimizing human error) and standardization of test administration and automatic scoring (minimizing sources of response bias). Today, they can be used, according to the clinician experience, as an alternative to «paper and pencil tests " in clinical research and practice. The advantage is a better usability but they do not improve ecological validity of the assessment. In fact, for a research study, ecological validity means that methods, material and settings of the study approximate a real-world context that is being examined. Experience sampling methodology (ESM) is a potential way to achieve this goal. ESM refers to a set of empirical methods that are designed to allow respondents to document their thoughts, feelings and actions outside the walls of a laboratory and within the context of everyday life [20] (E). ICT and most particularly wearable smart phones can be of interest for the assessment of cognition. This has been already done for working memory evaluations [21] (E) and could be applied as well to episodic memory tasks. For instance, as part of the cohort study AMI (Agrica-MSA-ISPED) [22] (E) of 1002 retired farmers, an ancillary project has been developed in which 60 subjects 
received an MRI with the use of the mobile phone PALM. This phone allowed to collect four times a day during a week (Computerized Ambulatory Monitoring) information regarding the activities of daily living of the subjects as well as their performances in neuropsychological tests of semantic memory and episodic memory. The obtained results of these tests are better associated with the brain imaging data (size of the hippocampus in particular) as with the test results conducted by neuropsychologists.

Following these examples the expert panel underlined the interest to develop simple devices with easy and understandable scores, with as added value, in comparison to the present tools, ecological validity, reliability and limitation of the interjudge variability.

\section{BEHAVIORS:}

Behavioral and psychological symptoms of dementia (BPSD) are frequently associated with cognitive deficits during the progression of Alzheimer disease (AD) and other dementia. BPSD assessment is usually based on a structured interview, using subjective input from either the caregiver and/or the patient. For instance apathy, which is the most frequent BPSD, [23] (E) is usually assessed in clinical practice and research with the Neuropsychiatric Inventory (NPI) apathy domain. It has also been proposed that ICT such as actigraphy could provide an objective assessment.

This demonstrates that ICT use could be a source of additional information for the assessment of BPSD.

Other ICT tools can also be used for the assessment and the understanding of motor 
disturbances. Recently, Robinovitch [24] (E) demonstrated that Digital video cameras installed in common living areas (dining rooms, lounges, hallways) may provide insight into the sequences of events that most commonly lead to falls and, further to more valid and effective approaches for balance assessment and fall prevention in long-term care.

\section{ACTIVITIES OF DAILY LIVING:}

Behavior is not only BPSD but also the ability of a subject to be involved in activities of daily living [25] (E). One of the key clinical features of Alzheimer's disease (AD) is impairment in daily living functioning [26] (E).

The inability to perform Instrumental Activities of Daily Living (ADL) [27] (E) is present from the early stages - of cognitive decline [28] (E). As indicated in the recommendations from the NIA-AA [29] (E) persons with Mild Cognitive Impairment (MCl) commonly have slight problems performing complex tasks [30] (E). Methods to assess IADL comprise self-reported questionnaires, performance-based assessment and informant-based questionnaires. These measurements have some limitations because they do not offer accurate, reproducible, objective and ecological perspectives. Moreover, these assessment batteries and standardized tools rely on quantitative scales, which are often lacking sensitivity. For this reason, information and communication technology (ICT), in particular, techniques involving imaging and video processing are of interest, and may overcome these limitations by reducing the inter/intra rater variability due to human interpretation bias.

Goal directed behavior (GDB) is another definition presented during the discussion. GDB is a construct used to operationalize a broad spectrum of purposeful actions and their determinants from the simplest single movement to the most complex 
patterns behaviors. GDB is a set of related processes (including cognition, emotion, motivation) by which an internal state is translated through action into the attainment of a goal [31] (E). It is important to differentiate the semi directed (prespecified) activities from self initiated GDB activities.

The first one can be directly assessed by proposing a patient to carry out a series of prespecified tasks[32] (E) and using this strategy it is possible to assess activities in real life time using ICT (Box 1) [33] (E).

The second one can also be tested by giving the patient a complex order (follow a recipe) and assess how he/she deals with the general recommendation in order to test initiation as well as execution. This type of assessment is very difficult to organize and time consuming.

Following these examples the expert panel underlines:

- For the assessment of BPSD objective data covering day and night behavior are needed

- BPSD real time assessment must be validated in comparison to the NPI domains.

- ICT devices enable the patients' performances and actions to be captured in real time and real life situations and to be accurately evaluated. This is particularly important for activities of daily living and the semi directed activities

- the potential interest of serious games for assessing self initiated goal directed behaviour should be explored

\section{2/ ICT sensors review and description}

Table 1 summarizes studies done in elderly subjects with $A D$ and related disorders. The general recommendations concerning the use of ICT are listed in table 2. The different types of sensors need to be simple and easy to use to avoid a population selection based on their ability to understand device utilization. Various potential sensors exist, and therefore, the choice should be done accordingly to study 
conditions (in a clinical consultation setting, in Nursing home, at home) and to population groups (patients, family caregiver, professional carer). Technical progress may allow the implementation of one device with multiple sensors (eg actigraphy, body temperature, audio recording). The choice of devices depends on available budget and agreements between clinicians, ICT engineers and end users. In addition the quality of sensor processing often depends on a correct installation / calibration and some sensors have practical issues such as battery life for wearable sensors or data storage/transmission.

Concerning the audio and video recording devices, it is particularly important to employ automatic recording and analysis of the data. This is crucial when long term monitoring is required, such as for the assessment of behavioural disturbances. In order to develop this type of automatic recording, clinicians must describe in full details to the ICT engineers the characteristics of the behavioural sequences that need to be captured.

Use of ICT devices in everyday life raises several issues that must be discussed in each specific situation. However, ICT tools utilization may also have some positive effects, at least for a short-term period, for example by involving more actively the patient or empower the couple patient/ caregiver in the assessment procedure.

The use of video recording devices (wearable or static) is particularly often discussed: "Is there any change in the way of life of the people when there is a camera in the room?" This is mostly depending on the person. However, long term use of such devices seems to indicate a good acceptance. Usually, the person only notices the presence of the video sensor at the beginning of the experimentation but 
this awareness disappears rapidly [34] (E). A very important factor to increase acceptance is the understanding of the reason for installing the sensor.

Furthermore, it is important to provide the subject with systematic feedback about the data that are collected.

In this respect, the experience sampling method using the psymate may be relevant [35]. The "Psymate" is a small electronic device that momentary assesses daily changes in functioning, emotions, which may contribute to identifying environmental risk factors and symptom patterns, as well as provide sensitive evaluations for treatment. This "PsyMate," was specifically developed to implement momentary assessment in clinical practice. It has been applied in psychotic patients, in whom it was shown that self-monitoring of both positive and negative psychotic symptoms is feasible, provides a much more detailed and fine-grained picture of symptoms, and reveals patterns of behavior that may be relevant for treatment. Furthermore, the PsyMate could be instrumental for real-time and real-world delivery of psychological interventions [36]. A trial using the Psymate for patients with dementia, and their caregivers is ongoing.

As these technologies rely on the acquisition of a large number of data collected in the context of the daily life of individuals, there is a need to consider first the respect of privacy and the protection of individual data. It is important to conduct this ethical reflection on a case-by-case basis for each project, as these innovative technologies may elicit specific ethical questions.

Concerning the output coming from the devices used for assessments, the following points have been underlined: 
- In everyday clinical practice the output (the clinical score) needs to be simple as possible and easily understandable. The score needs to be obtained automatically or at least be understandable to users without high technical competences.

(patient, caregiver, clinician, researcher).

- Correlation should be established between ICT scores and classical tools scores.

- ICT characteristics allow combining different scores coming from one single domain (cognition) or from different domains (e.g. cognition, motricity, emotion, nutrition). However, this type of combination needs to be defined and described in a preliminary step between the clinician and the engineers after taking into account the end user point of view [37] (E).

\section{3 / ICT in outcome measures for clinical trials for Alzheimer's disease}

Most of the information indicated in the previous sections can be applied as well to the particular case of clinical research.

It is possible to separate expert suggestions into two parts: the wishes and the requirements.

\section{$\underline{\text { Wishes; }}$}

- In clinical studies, including therapeutic pharmacological and non pharmacological trials, and most particularly cohort follow up studies, one of the major cause for drop outs is that patient are reluctant to return to the center. With the use of ICT, it may be possible to assess cognition, behaviour and/or activities of daily living directly in the patient's home environment and by therefore decrease the number of visit in the center. 
- ICT use may be able to help to keep blinding about the evolution of the patient

- ICT may help to have a more objective and homogeneous assessment of behavioural disturbances and by reducing variability.

- The use of serious games can be of interest to train the investigator and/or staff members on how to rate or manage certain behavioural problems

- The association of ICT and biological data may help to foster new ideas and solve common medical problems (falls, sleep disorders). For example the ICT device can provide researchers with some information on sleep parameters (e.g. apnea, Co2 Level). Having a biological component being part of the discussion process could only aid to the hypothesis generation as well as to the hypothesis testing

\section{$\underline{\text { Requirements }}$}

Before using ICT devices in clinical trials, several steps need to be achieved:

- ICT needs to be accepted by as a valid study endpoint by Health Authorities. In fact, it seems hard to shift from a well establish end point into a surrogate marker. Unless we get this new endpoint to be approved, technologies are interesting but only as investigational technologies for clinical trial. This explains the importance of introducing ICT into clinical practice in a first step before getting it accepted as a validated clinical endpoint by drug regulators.

- It is important to understand the correlation between ICT data and results obtained by classical assessment tools. 
- For BPSD, long-term data need to be collected (24h during one month). It is particularly important to assess whether the frequency of the behavior described by the caregiver (using the NPI) is the same as the one recorded by the ICT device.

\section{CONCLUSION}

To summarize, special attention should be given to ICT solutions that provide personalized information and more objective assessment that indirectly help people with $A D$ and their caregivers to better understand BPSD and provide help with their daily living activities [38].

One of the obvious results of this ICT and Mental Health workshop is to allow the interaction between ICT engineers and health professionals. For clinicians it is important to establish the exact type of indicators that are clinically relevant and that can provide useful information in daily practice. Secondly, for ICT engineers, the challenge is to adapt the constraints of the technology to the needs of the clinician.

The adopted approach tries to emphasize the clinician's user needs. In the next step, more attention should be paid to the user needs from patient / caregiver and to tool designs considering end user perspectives. It is of great importance that patients and caregivers be engaged in the assessment process and be able to give feedback on the feasibility and tolerability of the ICT sensors.

List of abbreviations (order of appearance)

(AD) Alzheimer disease / (ICT) Information and Communication Technologies / (CoBTek) Cognition - Behaviour Technologies Research unit ; (CTAD) Clinical Trial in Alzheimer Disease congress / (NPS) Neuropsychiatric symptoms / (ADL) Activities of Daily Living / (NIA-AA) : National Institute on Aging-Alzheimer's Association workgroups / (MCl) Mild Cognitive Impairment / (GDB) Goal directed behavior

\section{Acknowledgments}

The ICT and Mental Health workshop was supported by by the Innovation Alzheimer association, The Centre National de Référence Santé à domicile et autonomie (CNR Santé) and grants from the ANR09-TECS-016-01 - TecSan - SWEET HOME, the FP7 Dem@care project 


\section{REFERENCES}

1. Folstein, Folstein, and McHugh, "Mini-mental state". A practical method for grading the cognitive state of patients for the clinician. J Psychiatr Res., 1975. 12(3): p. 189-98.

2. Rosen, W.G., Mohs, R.C., Davis, K.L., A new rating scale for Alzheimer's disease. Am J Psychiatry, 1984. 141: p. 1356-1364.

3. Cummings, Mega, Gray, Rosenberg-Thompson, Carusi, and Gornbein, The Neuropsychiatric Inventory: comprehensive assessment of psychopathology in dementia. Neurology, 1994. 44(12): p. 2308-2314.

4. $\quad$ Morris, J.C., The Clinical Dementia Rating (CDR): Current vision and scoring rules. Neurology, 1993: p. 2412-2414.

5. Dubois, B., H.H. Feldman, C. Jacova, J.L. Cummings, S.T. Dekosky, P. BarbergerGateau, A. Delacourte, G. Frisoni, N.C. Fox, D. Galasko, S. Gauthier, H. Hampel, G.A. Jicha, K. Meguro, J. O'Brien, F. Pasquier, P. Robert, M. Rossor, S. Salloway, M. Sarazin, L.C. de Souza, Y. Stern, P.J. Visser, and P. Scheltens, Revising the definition of Alzheimer's disease: a new lexicon. Lancet Neurol, 2010. 9(11): p. 1118-27.

6. McKhann, G.M., D.S. Knopman, H. Chertkow, B.T. Hyman, C.R. Jack, Jr., C.H. Kawas, W.E. Klunk, W.J. Koroshetz, J.J. Manly, R. Mayeux, R.C. Mohs, J.C. Morris, M.N. Rossor, P. Scheltens, M.C. Carrillo, B. Thies, S. Weintraub, and C.H. Phelps, The diagnosis of dementia due to Alzheimer's disease: recommendations from the National Institute on Aging-Alzheimer's Association workgroups on diagnostic guidelines for Alzheimer's disease. Alzheimers Dement, 2011. 7(3): p. 263-9.

7. Sampaio, C., Clinical relevance on Alzheimer's disease endpoints. J Nutr Health Aging, 2007. 11(4): p. 316-7.

8. Eghdam, A., J. Scholl, A. Bartfai, and S. Koch, Information and communication technology to support self-management of patients with mild acquired cognitive impairments: systematic review. J Med Internet Res, 2012. 14(6): p. e159.

9. Meijer, W.J. and P.L. Ragetlie, Empowering the patient with ICT-tools: the unfulfilled promise. Stud Health Technol Inform, 2007. 127: p. 199-218.

10. Clarkson, B.S.N., Pentland, A. , Auditory context awareness via wearable computing, in The Perceptual User Interfaces Workshop, P.o. PUI'98, Editor 1998. p. p. p. 37-42.

11. Wang, S., Common sense based joint training of human activity recognizers, in The 20th IEEE International Joint Conference on Artificial Intelligence P.o.I. 2007, Editor 2007. p. p. p. 2237- 42.

12. Foerster, F. and J. Fahrenberg, Motion pattern and posture: correctly assessed by calibrated accelerometers. Behav Res Methods Instrum Comput, 2000. 32(3): p. 450-7.

13. Hooghiemstra, A.M., L.H. Eggermont, P. Scheltens, W.M. van der Flier, J. Bakker, M.H. de Greef, P.A. Koppe, and E.J. Scherder, Study protocol: EXERcise and cognition in sedentary adults with early-ONset dementia (EXERCISE-ON). BMC Neurol, 2012. 12: p. 75.

14. Yesavage, Friedman, Kraemer, Noda, Wicks, Bliwise, Sheikh, Tinklenberg, and Zarcone, A follow-up study of actigraphic measures in home-residing Alzheimer's disease patients. J Geriatr Psychiatry Neurol, 1998. 11(1): p. 7-10. 
15. Nagels, Engelborghs, Vloeberghs, Van Dam, Pickut, and D. Deyn, Actigraphic measurement of agitated behaviour in dementia. Int J Geriatr Psychiatry, 2006. 21(4): p. 388-93.

16. Volkers, Tulen, Van Den Broek, Bruijn, Passchier, and Pepplinkhuizen, 24-Hour motor activity after treatment with imipramine or fluvoxamine in major depressive disorder. Eur Neuropsychopharmacol, 2002. 12(4): p. 273-8.

17. Banerjee, S., F. Steenkeste, P. Couturier, M. Debray, and A. Franco, Telesurveillance of elderly patients by use of passive infra-red sensors in a 'smart' room. J Telemed Telecare, 2003. 9(1): p. 23-9.

18. Chan, M., E. Campo, and D. Esteve, Assessment of activity of elderly people using a home monitoring system. Int J Rehabil Res, 2005. 28(1): p. 69-76.

19. Wild, K., D. Howieson, F. Webbe, A. Seelye, and J. Kaye, Status of computerized cognitive testing in aging: a systematic review. Alzheimers Dement, 2008. 4(6): p. 428-37.

20. Christensen, T.C., Feldman-Barrett, L., and E. Bliss-Moreau, Lebo, K., Kaschub C., $A$ Practical Guide to Experience-sampling Procedures. Journal of Happiness Studies 2003. 4: p. 53-78.

21. Kane, M.J., A.R. Conway, T.K. Miura, and G.J. Colflesh, Working memory, attention control, and the N-back task: a question of construct validity. J Exp Psychol Learn Mem Cogn, 2007. 33(3): p. 615-22.

22. Lassalle-Lagadec, S., M. Allard, B. Dilharreguy, P. Schweitzer, J. Swendsen, and I. Sibon, Linking MRI to daily life experience: the example of poststroke depression. Neurology, 2012. 78(5): p. 322-5.

23. Robert, P.H., et al., Proposed diagnostic criteria for apathy in Alzheimer's disease and other neuropsychiatric disorders. European Psychiatry, 2009. 24(2): p. 98104.

24. Robinovitch, S.N., F. Feldman, Y. Yang, R. Schonnop, P.M. Lueng, T. Sarraf, J. SimsGould, and M. Loughin, Video capture of the circumstances of falls in elderly people residing in long-term care: an observational study. Lancet, 2012.

25. Katz, S., A.B. Ford, R.W. Moskowitz, B.A. Jackson, and M.W. Jaffe, Studies of Illness in the Aged. The Index of Adl: A Standardized Measure of Biological and Psychosocial Function. JAMA, 1963. 185: p. 914-9.

26. Lakhan, P., M. Jones, A. Wilson, and L.C. Gray, The Decline in Activities of Daily Living at Discharge (DADLD) Index: Stratifying Patients at Lower and Higher risk. J Nutr Health Aging, 2012. 16(10): p. 919-24.

27. Lawton, M.P. and E.M. Brody, Assessment of older people: self-maintaining and instrumental activities of daily living. Gerontologist, 1969. 9(3): p. 179-86.

28. Tuokko, H., C. Morris, and P. Ebert, Mild cognitive impairment and everyday functioning in older adults. Neurocase, 2005. 11(1): p. 40-7.

29. Albert, M.S., S.T. DeKosky, D. Dickson, B. Dubois, H.H. Feldman, N.C. Fox, A. Gamst, D.M. Holtzman, W.J. Jagust, R.C. Petersen, P.J. Snyder, M.C. Carrillo, B. Thies, and C.H. Phelps, The diagnosis of mild cognitive impairment due to Alzheimer's disease: recommendations from the National Institute on Aging-Alzheimer's Association workgroups on diagnostic guidelines for Alzheimer's disease. Alzheimers Dement, 2011. 7(3): p. 270-9.

30. De Vriendt, P., E. Gorus, E. Cornelis, A. Velghe, M. Petrovic, and T. Mets, The process of decline in advanced activities of daily living: a qualitative explorative study in mild cognitive impairment. Int Psychogeriatr, 2012. 24(6): p. 974-86. 
31. Brown, R.G. and G. Pluck, Negative symptoms: the 'pathology' of motivation and goal-directed behaviour. Trends Neurosci, 2000. 23(9): p. 412-7.

32. Shallice, T. and P.W. Burgess, Deficits in strategy application following frontal lobe damage in man. Brain, 1991. 114 (Pt 2): p. 727-41.

33. Sacco, G., V. Joumier, N. Darmon, A. Dechamps, A. Derreumaux, J.H. Lee, J. Piano, N. Bordone, A. Konig, B. Teboul, R. David, O. Guerin, F. Bremond, and P. Robert, Detection of activities of daily living impairment in Alzheimer's disease and mild cognitive impairment using information and communication technology. Clin Interv Aging, 2012. 7: p. 539-49.

34. Zouba, N., Bremond,F., Anfonso,A., Thonnat, M., Pascual, E., Guerin, O, Monitoring elderly activities at home. Gerontechnology, 2010. 9(2).

35. Myin-Germeys, I., M. Birchwood, and T. Kwapil, From environment to therapy in psychosis: a real-world momentary assessment approach. Schizophr Bull, 2011. 37(2): p. 244-7.

36. Wichers, M., C.J. Simons, I.M. Kramer, J.A. Hartmann, C. Lothmann, I. MyinGermeys, A.L. van Bemmel, F. Peeters, P. Delespaul, and J. van Os, Momentary assessment technology as a tool to help patients with depression help themselves. Acta Psychiatr Scand, 2011. 124(4): p. 262-72.

37. Mulin E., Joumier V., Leroi I., Lee J.H., Piano J., Bordone N., Derreumeaux A., Malléa P., Brocker P., Dechamps A., Romdhane R., Thonnat M., Bremond F., David R., Robert P. Functional dementia assessment using a video monitoring system: Proof of concept. Gerontechnology, 10(4) : 244-248, 2012

38. Lauriks, S., A. Reinersmann, H.G. Van der Roest, F.J. Meiland, R.J. Davies, F. Moelaert, M.D. Mulvenna, C.D. Nugent, and R.M. Droes, Review of ICT-based services for identified unmet needs in people with dementia. Ageing Res Rev, 2007. 6(3): p. 223-46.

39. Ivorra, A., C. Daniels, and B. Rubinsky, Minimally obtrusive wearable device for continuous interactive cognitive and neurological assessment. Physiol Meas, 2008. 29(5): p. 543-54.

40. Yesavage, J.A., L. Friedman, H.C. Kraemer, A. Noda, D. Wicks, D.L. Bliwise, J. Sheikh, J. Tinklenberg, and V. Zarcone, A follow-up study of actigraphic measures in home-residing Alzheimer's disease patients. J Geriatr Psychiatry Neurol, 1998. 11(1): p. 7-10.

41. Volkers, A.C., J.H. Tulen, W.W. van den Broek, J.A. Bruijn, J. Passchier, and L. Pepplinkhuizen, Motor activity and autonomic cardiac functioning in major depressive disorder. J Affect Disord, 2003. 76(1-3): p. 23-30.

42. Nagels, G., Engelborghs, S., Vloeberghs, E., Van Dam, D., Pickut, B.A., De Deyn, P.P., Actigraphic measurement of agitated behaviour in dementia. Int J Geriatr Psychiatry, 2006. 21(4): p. 388-93.

43. Mahlberg, R. and S. Walther, Actigraphy in agitated patients with dementia. Monitoring treatment outcomes. Z Gerontol Geriatr, 2007. 40(3): p. 178-84.

44. Müller, U., Czymmek, J., Thöne-Otto, A. \& Von Cramon, D, Reduced daytime activity in patients with acquired brain damage and apathy: A study with ambulatory actigraphy. Brain Injury, 2006. 20(2): p. 157-160.

45. Mulin, E., Zeitzer, J.M., Friedman, L., Le Duff, F., Yesavage, J., Robert, P.H., David, R., Relationship between apathy and sleep disturbance in mild and moderate Alzheimer's disease: an actigraphic study. Journal of Alzheimer's Disease, 2011. 25(1): p. 85-91. 
46. David, R., Ambulatory actigraphy correlates with apathy in mild Alzheimer's disease. Dementia: The International Journal of Social Research and Practice, 2010. 9(4): p. 509-516.

47. David, R., Mulin, E., Friedman, L., Duff, F.L., Cygankiewicz, E., Deschaux, O., Garcia, R., Yesavage, J.A., Robert, P.H., Zeitzer, J.M., Decreased Daytime Motor Activity Associated With Apathy in Alzheimer Disease: An Actigraphic Study. Am J Geriatr Psychiatry, 2012. 20 (9) : p. 94-97.

48. Kuhlmei, A., Walther, B., Becker, T., Müller, U., Nikolaus, T., Actigraphic daytime activity is reduced in patients with cognitive impairment and apathy. European Psychiatry, 2011: 28 (2) : p. 806-814.

49. Hatfield, C.F., J. Herbert, E.J. van Someren, J.R. Hodges, and M.H. Hastings, Disrupted daily activity/rest cycles in relation to daily cortisol rhythms of homedwelling patients with early Alzheimer's dementia. Brain, 2004. 127(Pt 5): p. 1061-74.

50. Reiterer, V., C. Sauter, G. Klosch, W. Lalouschek, and J. Zeitlhofer, Actigraphy--a useful tool for motor activity monitoring in stroke patients. Eur Neurol, 2008. 60(6): p. 285-91.

51. Meadows, R., R. Luff, I. Eyers, S. Venn, E. Cope, and S. Arber, An actigraphic study comparing community dwelling poor sleepers with non-demented care home residents. Chronobiol Int, 2010. 27(4): p. 842-54.

52. Suzuki, R., S. Otake, T. Izutsu, M. Yoshida, and T. Iwaya, Monitoring daily living activities of elderly people in a nursing home using an infrared motion-detection system. Telemed J E Health, 2006. 12(2): p. 146-55.

53. Suzuki, T. and S. Murase, Influence of outdoor activity and indoor activity on cognition decline: use of an infrared sensor to measure activity. Telemed J E Health, 2010. 16(6): p. 686-90.

54. Suzuki, T., S. Murase, T. Tanaka, and T. Okazawa, New approach for the early detection of dementia by recording in-house activities. Telemed J E Health, 2007. 13(1): p. 41-4.

55. Dodge, H.H., N.C. Mattek, D. Austin, T.L. Hayes, and J.A. Kaye, In-home walking speeds and variability trajectories associated with mild cognitive impairment. Neurology, 2012. 78(24): p. 1946-52.

56. Nakano, T., E. Koyama, T. Nakamura, T. Ito, K. Tamura, and M. Yaginuma, Use of an infrared sensor system to take long-term bedside measurements of rest-activity patterns in the elderly with dementia. Psychiatry Clin Neurosci, 2002. 56(3): p. 287-8.

57. Romdhane, R., E. Mulin, A. Derreumeaux, N. Zouba, J. Piano, L. Lee, I. Leroi, P. Mallea, R. David, M. Thonnat, F. Bremond, and P.H. Robert, Automatic video monitoring system for assessment of Alzheimer's disease symptoms. J Nutr Health Aging, 2012. 16(3): p. 213-8.

58. Williams, K., A. Arthur, M. Niedens, L. Moushey, and L. Hutfles, In-Home Monitoring Support for Dementia Caregivers: A Feasibility Study. Clin Nurs Res, 2012.

59. Shoval, N., G.K. Auslander, T. Freytag, R. Landau, F. Oswald, U. Seidl, H.W. Wahl, S. Werner, and J. Heinik, The use of advanced tracking technologies for the analysis of mobility in Alzheimer's disease and related cognitive diseases. BMC Geriatr, 2008. 8: p. 7. 
60. Faucounau, V., M. Riguet, G. Orvoen, A. Lacombe, V. Rialle, J. Extra, and A.S. Rigaud, Electronic tracking system and wandering in Alzheimer's disease: a case study. Ann Phys Rehabil Med, 2009. 52(7-8): p. 579-87.

61. Elgethun, K., R.A. Fenske, M.G. Yost, and G.J. Palcisko, Time-location analysis for exposure assessment studies of children using a novel global positioning system instrument. Environ Health Perspect, 2003. 111(1): p. 115-22.

62. Werner, S., G.K. Auslander, N. Shoval, T. Gitlitz, R. Landau, and J. Heinik, Caregiving burden and out-of-home mobility of cognitively impaired care-recipients based on GPS tracking. Int Psychogeriatr, 2012. 24(11): p. 1836-45.

63. Wahl, H.W., M. Wettstein, N. Shoval, F. Oswald, R. Kaspar, M. Issacson, E. Voss, G. Auslander, and J. Heinik, Interplay of Cognitive and Motivational Resources for Out-of-Home Behavior in a Sample of Cognitively Heterogeneous Older Adults: Findings of the SenTra Project. J Gerontol B Psychol Sci Soc Sci, 2012.

64. Rantz, M.J., M. Skubic, and S.J. Miller, Using sensor technology to augment traditional healthcare. Conf Proc IEEE Eng Med Biol Soc, 2009. 2009: p. 6159-62.

65. Kidd, C.D., Orr, R., Abowd, G.D., Atkeson, C.G., Essa, I.A., MacIntyre, B., et al., The Aware Home: A Living Laboratory for Ubiquitous Computing Research, in Proceedings of CoBuild'990ctober 1999, Position paper.

66. Helal, S., Mann, W., El-Zabadani, H., King, J., Kaddoura, Y., Jansen, E., The Gator Tech Smart House: a programmable pervasive space. Computer, 2005. 38(50-60).

67. Intille, S., Larson, K, Munguia Tapia E, Beaudin JS, Kaushik P, Nawyn J, Rockinson, R., Using a live-in laboratory for ubiquitous computing research, in Proceedings of PERVASIVE 2006; vol. LNCS, S.B. Fishkin KP, Nixon P, Quiley A, editors., Editor 2006: 3968. Berlin, Heidelberg: Springer-Verlag;. p. p. 349-65.

68. Cerni, M., Penhaker, M. Circadian rhythm monitoring in homecare systems. in 13th international conference on biomedical engineering. 2008. Singapore.

69. Demongeot, J., G. Virone, F. Duchene, G. Benchetrit, T. Herve, N. Noury, and V. Rialle, Multi-sensors acquisition, data fusion, knowledge mining and alarm triggering in health smart homes for elderly people. C R Biol, 2002. 325(6): p. 67382.

70. Tamura, T., T. Togawa, M. Ogawa, and M. Yoda, Fully automated health monitoring system in the home. Med Eng Phys, 1998. 20(8): p. 573-9.

71. Matsuoka, K. Aware home understanding life activities. Towards a humanfriendly assistive environment. in International conference on smart homes and health telematics. 2004.

72. Yamazaki, T. Beyond the smart home. in International conference on hybrid information technology. . 2006.

73. Cash, M., Assistive technology and people with dementia. Reviews in Clinical Gerontology, 2003. 13(4): p. 313-9.

74. Adlam, T., Gibbs, C., Orpwood, R., The Gloucester Smart House bath monitor for people with dementia. Phys Med, 2001. 17(3): p. 189.

75. Demiris, G. and B.K. Hensel, Technologies for an aging society: a systematic review of "smart home" applications. Yearb Med Inform, 2008: p. 33-40.

76. Woolham, J., Frisby, B., How techology can help people feel safe at home. Journal of Dementia Care, 2002. 10(2): p. 27-9.

77. Rialle, V., F. Duchene, N. Noury, L. Bajolle, and J. Demongeot, Health "Smart" home: information technology for patients at home. Telemed J E Health, 2002. 8(4): p. 395-409.

78. Marsh, J., House Calls. Rochester Review, 2002. 64(3): p. 22-6. 
79. Demiris, G., Skubic, M, Keller, J, Rantz, MJ, Parker Oliver D, Aud MA, et al., Nurse Participation in the Design of User Interfaces for a Smart Home System., in Proceedings of the International Conference on Smart Homes and Health Telematics, N.I. Belfast, Editor 2006. p. 66-73.

Table 1: Studies using ICT in elderly subjects and patients with AD and related disorders.

\begin{tabular}{|c|c|c|c|}
\hline Technologies & Authors & Subjects & Topic \\
\hline \multirow{16}{*}{ Actigraphy } & & & Minimally obtrusive wearable device for continuous \\
\hline & Ivorra et al., 2008 [39] & 10 volunteers & neurological assessment \\
\hline & Yesavage et al., 1998 [40] & $61 \mathrm{AD}$ patients & Sleep evaluation in dementia patients \\
\hline & Volkers et al., 2003 [41] & 67 depressed inpatients & Motor activity in major depressive disorder \\
\hline & Nagels et al., 2006 [42] & 110 dementia patients & Measurement of agitated behavior in dementia \\
\hline & Mahlberg et al., 2007 [43] & $24 \mathrm{AD}$ patients & Actigraphy in agitated patients with dementia \\
\hline & & & Actigraphy to measure reduced daytime activity in \\
\hline & Müller et al., 2006 [44] & 24 patients with acquired brain damage & damage and apathy \\
\hline & Mulin et al., 2011 [45] & 103 AD patients & Relationship between apathy and sleep disturbanc \\
\hline & David et al., 2010 [46] & $30 \mathrm{AD}$ patients & Actigraphy correlates with apathy in mild AD \\
\hline & David et al., 2011 [47] & 107 AD outpatients & Decreased daytime motor activity associated with \\
\hline & Kuhlmei et al., 2011 [48] & 82 participants & Daytime activity reduced in patients with cognitive \\
\hline & Hatfield et al., 2004 [49] & 27 dementia patients & Disrupted daily activity/rest cycles in relation to dail \\
\hline & Reiterer et al., 2008 [50] & 38 stroke patients & Motor activity monitoring in stroke patients \\
\hline & Meadows et al., 2010 [51] & 122 non-demented residents & Comparing community dwelling poor sleepers with \\
\hline & Foerster,et al., 2000 [12] & 31 subjects & Motion pattern and posture: correctly assessed by \\
\hline
\end{tabular}

Banerjee et al., 2003 [17] 4 elderly patients

Suzuki et al., 2006 [52] 3 elderly subjects
Telesurveillance of elderly patients by use of passi Monitoring daily living activities of elderly in a nurs 
Suzuki et al., 2010 [53]

Suzuki et al., 2007 [54]

Dodge et al., 2012 [55]

Nakano et al., 2002 [56]

Chan et al., 2005 [18]
53 elderly subjects

14 subject's houses

54 participants

2 dementia patients

4 participants
Influence of outdoor activity and indoor activity on

Early detection of dementia recording in-house act

In-home walking speeds and variability trajectories

Long-term bedside measurements of rest-activity $p$

Assessment of activity of elderly people using hom
Computerized Video Analyses
Romdhane et al., 2012 [57] 3 elderly (2 AD, 1 Control)

Sacco et al., 2012 [33] 64 participants (AD, MCl, Controls)

Williams et al., 2012 [58] 1 dyad (dementia patient/caregiver)

Robinovitch et al., 2012 [24] 130 individuals
Video Monitoring system for assessment of AD sy Detection of activities of daily living impairment In-Home Monitoring support for dementia caregive Video capture of the circumstances of falls in elder
Tracking technologies Shoval et al., 2008 [59]

Faucounau et al., 2009 [60]

Elgethun et al., 2003 [61]

Werner et al., 2012 [62]

Wahl et al., 2012 [63]

Chan et al., 2005 [18]

Rantz et al., 2009 [64]
360 demented persons

dyad (dementia patient/caregiver)

11 children

76 dyads(dementia patient/caregiver)

222 older adults

Not indicated

1 case study
Analysis of mobility in $A D$

Electronic tracking system and wandering in $A D$

Time-location analysis for exposure assessment st Caregiving burden and out-of-home mobility of cog Interplay of cognitive and motivational resources fo Assessment of activity of elderly people using a ho Using sensor technology to augment traditional he

\section{Target audience}

\section{SMART Homes}

\section{Health Data}

Monitoring
Kidd et al., 1998 [65]

Helal et al., 2005 [66]

Intille et al., 2006 [67]

Cerni et al., 2006 [68]

Chan et al., 2005 [18]

Demongeot et al., 2008 [69]

Tamura et al., 1998 [70]
Older adults and their families

Older adults and persons with disabilities

General population

General population

Older adults at home

Older adults at home

Older adults and persons with disabilities
AWARE Home, Georgia Institute of Technology

The Gator Tech Smart House: a programmable pe PlaceLab (part of House_n project of MIT) Circadian rhythm monitoring in homecare system PROSAFE, multisensor remote monitoring system Health Integrated Smart Home HIS, Information sy 


\begin{tabular}{|c|c|c|}
\hline Matsuoka et al., 2004 [71] & Older adults and persons with disabilities & Smart house in Osaka \\
\hline Yamazaki et al., 2006 [72] & Residents of assisted living facility & The Ubiquitous Home project \\
\hline Cash et al., 2001 [73] & Persons with early dementia & ENABLE Project \\
\hline Adlam et al., 2000 [74] & Persons with dementia & Gloucester Smart House UK \\
\hline Cook et al., 2001 [75] & General population & MavHome University of Texas at Arlington \\
\hline Woolham et al., 2000 [76] & Persons with dementia & Safe-at-home project, UK \\
\hline Rialle et al., 2004 [77] & Persons with dementia & Seven Oaks project \\
\hline Marsh et al., 2001 [78] & $\begin{array}{l}\text { General population with strong focus on } \\
\text { older adults }\end{array}$ & Smart Medical Home, Center for Future Health, Un \\
\hline Demiris et al., 2006 [79] & Residents of assisted living facility & Tiger Place, University of Missouri-Columbia \\
\hline
\end{tabular}

Tables 2 : Sensors characteristics according to recommendations and types:

\section{Characteristics}

- Sensitive to change in the type and intensity of patient activity

- Sensor easy to install / wear

- Immediate output for the clinician

- Self explanatory (easy explanation) for the user

- Understandable feed back information for the clinician

- Easy maintenance of the equipment

\section{Sensors types:}

- Accelerometry/Actigraphy

- Video 2\&3D - ambient

- Video 2\&3D - wearable

- Speech tracking

- Multi modal sensors

- Infra-red sensors

- Tracking technologies (Global Positioning System)

- Smart Phone and Tablet

- Serious game 